\title{
GEOBOTÂNICA DO DISTRITO FEDERAL E DE BRASÍLIA.
}

A idéia da mudança da Capital do Brasil para o planalto de Goiás apareceu pela primeira vez no ano de 1808 no "Correio Brasiliense" e, em seguida, em outras publicações, até finalmente tornar-se plano concreto na Constituição de 1891 que estabeleceu no Artigo 3 a transferência da Capital para o coração do Brasil. A Comissão de exploração da área do futuro Distrito Federal que procedeu à demarcação, sob a chefia do Dr. Luís Cruls, publicou seus trabalhos em $1893 \mathrm{em}$ relatório parcial. O Relatório definitivo publicado em 1906 abrange as contribuições das diferentes comissões de estudos, entre outras também a do botânico $\mathrm{E}$. Ule.

O coração do Brasil fica mais a oeste de Brasília, em plena selva eqüatorial e, sendo região insalubre, a escôlha recaiu sôbre o planalto. Escreve a respeito do clima do planalto o General Hastínfilo de Moura que integrou a comissão exploradora afirmando que

"qualquer que seja outro local preferido, não congregará tôdas as vantagens concentradas no que foi favorecido pela natureza, coordenadas, cotejadas e analisadas pela Comissão Cruls. Clima não há melhor no Brasil; água em qualidade, será encontrada tão boa, mas em abundância duvido. Nunca me fôra dado ver tanta profusão do precioso líquido, em eterna drenagem cósmica, como nessa região privilegiada, onde brotam infinidades de olhos dágua, vertentes límpidas, mananciais copiosos, nos quais o viandante mitiga sêde, sorvendo pura linfa, com deleitosa volúpia. Água e clima, dois imprescindiveis elementos à vida humana, fontes de saúde e vigor que, usufruídos sob observância de modernos preceitos de higiene e nutrição, salutar influência exercerão sôbre eugenia da raça, ainda deficientemente caracterizada entre nós" (1).

(1). - Cruls (L.), Relatório da Comissão Exploradora do Planalto Central do Brasil. Companhia Editôra Nacional. São Paulo, 1947, pág. XI. 
A. Glaziou que era também membro da referida comissão, ao ser interpelado pelo Dr. Cruls para dar sua opinião com respeito à região e seu clima declara:

"O aspecto das regiões até hoje percorridas é de um pais ligeiramente ondulado; lembra-me o Anjou, a Normândia e mais ainda a Bretanha, exceto todavia na direção Oeste onde campeia a Serra dos Pirineus, tão pitoresca. A Leste, estende-se o belo vale que vai prolongando-se até aos pequenos montes do rio Paraná, ramificando-se, em outros pontos, em tôdas as direçōes. Esta planície imensa, de superfície tão suavemente sinuosa, é riquissima de cursos dágua límpida e deliciosa que manam da menor depressão do terreno. Essas fontes, como os grandes rios que regam a região são protegidas por admiráveis capões aos quais nunca deveria golpear o machado do homem, senão com a maior circunspeção. São magníficos os pastos e certamente superiores a todos os que vi no Brasil Central. Todos êsses elementos cuja disposição se poderia atribuir à inspiração de um artista sublime dão à paisagem o aspecto mais aprazivel e de que não há nada comparável, a não ser em miniatura os antigos parques inglêses desenhados por Le Notre ou Paxton" (2).

Pela Constituição de 1891 o nôvo Distrito Federal deveria ter uma área de 14.400 quilômetros quadrados, à qual a comissão exploradora deu a figura de um retângulo com 160 quilômetros de direção LO e de 90 quilômetros em direção NS, sendo que a coordenada oriental passava exatamente pela cidade de Formosa.

A área demarcada em 1892 foi reduzida, entretanto, a 5.500 quilômetros quadrados, com as dimensões de 90 por 60 quilômetros aproximadamente, ficando porém dentro da área primitiva e passando os limites orientais perto de Formosa (esta cidade já fora do Distrito Federal), seguindo o curso do Ribeirăo Santa Rita e do Rio Prêto, e a coordenada setentrional passando pelo paralelo $15,30^{\prime}$. Os limites ocidentais seguem o curso do Rio Descoberto e a coordenada austral o paralelo 15,05'. Para tornar possível a construção da nova Capital e legitimar a posse dos terrenos destinados ao nôvo Distrito $\mathrm{Fe}$ deral, o Estado de Goiás transferiu em 18 de fevereiro de 1957 para os domínios do Govêrno Federal a área de 30.933 .739 alqueires geométricos.

(2). - Cruls (L.), op. cit., pág. 7 . 
Esta grande área é o divisor das águas das cabeceiras das duas grandes bacias hidrográficas: Prata e Amazonas, constituído de um imenso chapadão, limitado por algumas elevações e depressões, por onde os rios escoam.

Para localizar a sede da futura Capital foi escolhido em 1922 um ponto dentro do "Retângulo Cruls", distante 8 quilômetros da cidade de Planaltina onde se lançou uma pedra fundamental e se levantou um pequeno monumento comemorativo. Foi abandonado, entretanto, êste ponto e escolhido outro sítio. Para êste fim, em 1956, uma firma norte-americana, Belcher Associated Inc., de Ithaca, New York, foi encarregada de realizar os estudos do local mais indicado. Entre os cinco sítios apontados, uma comissão especial escolheu o "Sítio Castanho" situado a 25 quilômetros a sudoeste de Planaltina e a 18 quilômetros do dito monumento. O sítio é compreendido pelo Riacho Fundo e o Ribeirão Bananal, os quais ao se unirem formam o Rio Paranoá. Decidiu-se construir uma reprêsa nesse rio, três quilômetros abaixo da confluência daquêles tributários. Esta reprêsa tem duas finalidades, a saber: formar um lago para amenizar o clima, embelezar a nova Capital e construir uma usina hidrelétrica para supri-la de suas necessidades de energia.

No "Sítio Castanho" construiu-se a nova Capital: Brasília. Está sita numa paisagem levemente ondulada. Quando se vê pela primeira vez, ao se dobrar a crista de um divisor de águas, de quem vem de São Paulo, apresenta-se no chapadão longínqüo como uma fata-morgana o complexo de edifícios altos e brancos de Brasília, no meio do cerrado que impera naquela região (3).

O aspecto geral do Distrito Federal é de grandes planuras, cujas altitudes oscilam em tôrno de mil metros. Postado nos vales os relêvos aparecem como serras, limitadas por encostas relativamente íngremes. Mas vistos do alto do chapadão aparecem apenas como pequenos morros. Mesmo a Serra dos $\mathrm{Pi}-$ reneus (que fica já fora da área do Distrito Federal) e tem 1.400 metros $\mathrm{s} / \mathrm{m}$ forma só uma pequena saliência na superfície geral de mil metros em que está situado. O relêvo do planalto aplainado pela erosão milenar é um chapadão ou peneplano situado entre as cotas de 800 a 1.000 metros: aí estão os cursos superiores dos rios com vales geralmente largos entre 700 a

(3). - Aubreville (A.), Les forêts du Brésil, in "Bois et forêtu des tropiques". Paris, 1958, n.0 60, figs. 11 e 16 . 
900 metros s/m. Os cursos inferiores são, em geral, fortemente encaixados, entre 400 a 600 metros. Entre os cursos inferiores e superiores a erosão remontante formou quedas dágua ou corredeiras. Sôbre um embasamento de rochas cristalinas antigas (do arqueano e algonquiano) repousam sedimentos (mesozóicos do triássico e cretáceo). As rochas cristalinas são micachistos, gneisses e quartzitos; os sedimentos domiantes são arenitos. $\mathrm{Na}$ orla oriental os sedimentos são constituídos por folhelhos e calcáreos (do siluriano), ao sul aparecem nos vales os lençóis de efusivos basálticos, ao nordeste tufos vulcânicos e, a oeste, afloram eruptivas básicas (4).

O solo é, por isso, coberto de areia, pedregulho e, além disso, de concreções ferruginosas resultantes das crostas de ferro e laterite, chamadas canga. A canga cobre áreas vastas de poucos metros de espessura formando camadas horizontais características; nos chapadões a canga pouco extensa é permeável, de maneira que absorve as águas pluviais. A existência dessa camada protege o solo contra o runoff e erosão; o calcáreo é também poroso, de sorte que se podem formar lençóis dágua a 10 e 20 metros de profundidade sôbre a rocha madre. Éste é um dos fatos mais importantes do planalto central; revelam a sua existência os lagos rasos sôbre as chapadas e os inúmeros olhos dágua nos declives. Riachos e rios alimentados por estas nascentes têm água mesmo no fim da estação sêca (5).

A vegetação é formada essencialmente de cerrados e cerradões. Nos vales estabelecem-se os capões e as matas ciliares (ao longo dos cursos dágua) que às vêzes se estendem até as encostas. Entre as árvores do cerrado formam-se às vêzes campos limpos (sem arvoredo). As matas surgem onde há calcário e solo fértil, em ambiente úmido (6).

A coincidência entre vegetação e qualidade da terra é tão estreita que as duas podem melhor ser estudadas e compreendidas quando são descritas em conjunto. Quando a floresta e o campo são examinados em detalhe, nota-se que diferem um do outro não só quanto à sua composição florística e fisionômica, mas também quanto às exigências em água e riqueza mineral do solo. Assim, mata e campo são mais que dois tipos de vegetação, são tipos de terra com repercussão

\footnotetext{
(4). - Macedo Soares Guimarães (Fábio), o Planalto Central e o problema da mudança da Capital do Brasil, in "Revista Brasileira de Geografia". Rio de Janeiro, n.0 4, pág. 473.

(5). - Waibel (Leo), Vegetation and land use in the Planalto Central of Brazil, in "Geographical Review". New York, 1949, pág. 533

(6). - Macedo Soares Guimarães (F́́bio), op. cit., pág. 480.
} 
na sua utilização e possibilidades futuras. Há vários tipos de terras de mata e dois tipos já identificados de terras de campo (7).

A flora de Goiás é riquíssima, como mostra uma consulta demorada da "Flora Brasiliensis" de Martius e outras obras mais recentes. Grisebach avalia em dez mil o número de espécies existentes na região do planalto. Esta vasta região ainda não foi explorada intensivamente; são poucos os que viajaram por aquelas terras e alguns dos viajantes naturalistas percorreram-nas em tempo de estiagem quando quase não havia flôres e os campos estavam sêcos ou queimados. Alguns dentre êles seguiram apenas as estradas públicas registrando as plantas da margem. Os botânicos que penetraram no planalto foram Martius, E. Pohl e A. de Saint-Hilaire. E' com êles que começou de 1817 em diante, e são êles que mais contribuiram para o conhecimento da flora goiana. Outros são Riedel, G. Gardner, H. A. Weddell, W. J. Burchell, A. F. M. Glaziou, E. Ule e outros nacionais e estrangeiros. Em geral vasculharam melhor as matas e a maioria dêles herborizou fora do atual Distrito Federal. Os botânicos da "Comissão Cruls" foram Ule e Glaziou. Este último, bem como Gardner, não indicaram a localidade onde encontraram as plantas herborizadas. Aliás torna-se difícil conhecer o "locus classicus" das plantas colhidas, porque os nomes das vilas e cidades mudaram de nome e porque muitas vêzes os herborizadores indicaram Engenhos, Fazendas, prédios e pousos que na éra atual não mais são encontrados. Ule (8) trouxe das suas viagens de exploração 450 números de fanerógamas e 310 números de criptógamas, tendo atravessado o atual Distrito Federal desde os Montes Pireneus até Formosa com sua vegetação quàse exclusivamente de cerrados dos chapadões. Além de botânicos têm visitado e herborizado também geógrafos que muito contribuiram para melhor conhecimento daquelas regiões interessantes. Ültimamente, em 1956, veio a "Machris Brazilian Expedition" enriquecer os nossos conhecimentos sôbre a flora e fauna de Goiás, porém, as herborizações (de 2.200 números de plantas) tiveram lugar nas nascentes do Tocantins, fo-

\footnotetext{
(7). - Falssal (Speridião), o problema do desenvolvimento agricola do sudoeste do Planalto Central do Brasil, in "Revista Brasileira de Geografia". 1957, n. ${ }^{\circ}$ 1, pág. 25.

(8). - Cruls (L.), op. cit., pág. 233.
} 
ra do Distrito Federal. Em todo caso, a descrição da região e de sua flora servem de comparação e trazem novas luzes (9).

Analisaremos a vegetação classificando-a pelo sistema fisionômico criado pelo botânico A. Engler que dividiu o conjunto das plantas em seis grandes classes, a saber: halófilas (litorâneas), hidrófilas, higrófilas megatermais, higrófilas mesotermais, sub-xerófilas e xerófilas (10).

\section{Formação hidrófila.}

A esta formação pertencem aquelas plantas que crescem dentro da água ou ao longo dos cursos dágua perenes, nas margens dos lagos e nos terrenos úmidos, pantanosos e alagadiços. Caracterizam-se pelo tamanho grande das fôlhas, destinadas à evaporação rápida da água, pela côr verde-escura e ausência de pêlos e outro indumento epidérmico que poderiam retardar a evaporação.

As matas desta formação dividem-se em firmes e alagadiças. As primeiras diferem pouco das da formação higrófila megatermal e delas procedem as melhores madeiras e grande parte das nossas espécies extrativas. As plantas dos terrenos alagadiços são geralmente árvores raquíticas entremeadas de palmeiras, como sejam o buriti (Mauritia vinifera Mart.), buritirana (M. aculeata HBK.), os tucum (Bactris sp. e Astrocaryum sp.), a imbaúba (Cecropia sp.) com suas raízes sôbre andas, e muitas outras árvores, gramíneas, ciperáceas e Citamineas (11).

Nos campos hidrófilos ou pantanosos predominam as gramíneas e ciperáceas e outras plantas herbáceas próprias dêste ambiente úmido, como sejam: Xyris lacerata Pohl, Paepalanthus lamarckii Kth. e muitas outras espécies, a herva de bicho (Polygonum sp.), o canudo de pito (Ipomoea fistulosa Mart.), etc. Esses campos depois das chuvas constituem os melhores pastos para engorda de gado (12).

\footnotetext{
(9). - The Machris Brazilian Expedition, in "Contrib. in Science". Los Angeles. County Museum, 1957-1960, n.os 1-35.

(10). - Hoehne (F. C.), A flora do Brasil, in "Recenseamento do Brasil". 1922, vol. 1, págs. 127-136. Cf. Rawitscher (F. K.), Problemas de Fitoecologia com consideraçōes especiais sôbre o Brasil meridional, in "Botâníca", n.o 3. 1942, pág. 58 .

(11). - Hoehne (F. C.), op. cit., págs. 130-131.

(12). $\rightarrow$ Hoehne (F. C.), op. cit., págs. 131-134; cf. Rawitscher (F. K.), op. cit., pág. 58.
} 
A esta formação está subordinada também a vegetação aquática dos rios, a lacustre e a limnófila. Da flora aquática podemos citar os gôlfos (Nymphaea sp., Cabomba Warmingii Ule), o chapéu de couro (Echinodorus paniculatus Micn.), o jacinto dágua (Pontederia ovalis Mart.), os Alisma subulatum L., Hydrocleis Humboldtii Endl., Sagittaria rhombifolia Lam., Osmunda palustris Schrad. e a submersa Potamogeton polygonus Cham. et Schl. Entre as plantas flutuantes temos os aguapés (Eichhornia sp.), Santa Luzia dágua (Pistia stratiotes L.), lentilha dágua (Lemna sp.), as Salvinia e Azolla, Utricularia sp. e algas, como sejam Nitella, Spirogyra e Riccia. Nas rochas das corredeiras e das cachoeiras criam-se as larvas dos temidos borrachudos e piuns que vivem apegadas às plantas aquáticas de Tristicha hypnoides Tul., Mourera Weddelliana Tul. e muitas outras.

\section{Formações higrófilas.}

A vegetação higrófila gosta de abundantes precipitações atmosféricas. Desenvolve-se nas encostas dos montes onde as neblinas e o orvalho são freqüentes, mas tem sua maior extensão nos vales úmidos.

A fisionomia desta formação é de matas mais ou menos densas que muda segundo a altitude, exposição e altura dos montes, havendo transições das formações megatermais (com temperaturas elevadas) para formações mesotermais (com temperaturas médias, ao menos durante as noites) .

\section{Formações higrófilas megatermais.}

Fazem parte destas formações as matas frondosas com duas ou três sinúsias que surgem nos vales, a certa distância dos rios (que ficam em nível inferior) e, portanto, não inundados. Estendem-se, às vêzes, até o sopé e a encosta dos montes. (As matas raquíticas que crescem nas encostas mais elevadas, nas chapadas e nos picos dos montes pertencem à categoria das formações mesotermais). Cada uma dessas formações dividem-se ainda, de acôrdo com a pujança, densidade da vegetação, qualidade do solo e sua abundância em água, em outras sub-classes.

Às vêzes, a brusca interrupção da mata, nas encostas ou na planície não é conseqüência do clima, mas geralmente devida à constituição geológica do solo, ao afloramento de rochas ou à insuficiência da água no solo.

Assim, podem aparecer campos entre os trechos de mata, devido à secura e exigüidade do solo, mas também capões nas 
depressões onde a umidade e o humus persistem, mas então, de aspecto muito mais pobre que nas matas mais baixas.

As matas, os habitantes de Goiás as dividem em matas de primeira e segunda classes.

A mata de primeira classe surge nos terrenos onde o solo deriva das rochas vulcânicas (gabros e diorite) e, portanto, de terra rôxa e vermelha, friável e rica em humus. A maior formação de mata desta classe é o assim chamado "Matogrosso de Goiás" que fica em altitudes inferiores a mil metros, nos leitos cavados pelas águas fluviais. Esta mata começa em Anápolis e continua para o norte estendendo-se lá ao longo dos rios Maranhão e Paranoá com 20 mil quilômetros quadrados e 80 a 120 quilômetros de largura (13).

A mata é exuberante dando aquela suave sensação de quietude e aquêle frescor que a sombra e a vegetação verde proporcionam, em completa oposição ao cerrado que é enervante, ensolarado e quente. Mas o cerrado não apresenta a praga dos pernilongos que aí não encontram ambiente favorável para se criarem (na água parada e nos remansos), ao passo que na mata êles são abundantes (14).

As essências florestais que nela se encontram são muitas, em geral as mesmas que nas matas tropicais do interior, a saber, segundo Paulo de Souza (15), os jatobá, cedro, peroba, paineira, tamboril, aroeira, bálsamo, pau-brasil, jacarandá, guarabú, gonçalo-alves, braúna, garapa, vinhático, pau-marfim, sebastião-de-arruda, ipê, angelim, maçaranduba, jequitibá, pau-pereira, angico, cajarana, sucupira, guatambú, caixeta, aderno, pororoca, açoita-cavalo, gameleira-de-fôlha-larga, paude-óleo, mandiocão, vassourinha, peroba branca, cascudo, mangabeira-do-mato, marmelada-de-cachorro, taipoca, canela, pombeiro, jangada, aroeirinha, moreira, goiabeira-do-mato, mangabeira brava, piúna, pau caiado, fruto-de-macaco, osso-de-anta, catinga-de-cotia, pindaiba, joão-mole, cabreúva parda, fôlhade-bolo e cacunda. Saint Hilaire (16) cita ainda a mutamba e o xixá.

A mata de segunda classe é constituída de árvores de 15 a 20 metros de altura, mais baixas e mais distantes umas das ou-

(13). - Waibel (Leo), op. cit., pág. 536.

(14). - Rodrigues Ferreira (Manuel), Nos sertões do lendário Rio das Mortes. São Paulo. 1946. Editôra do Brasil S. A., pág. 39.

(15). - Souza (Paulo de), Apontamentos sôbre a flora de Goiás, in "Revista Florestal". Rio de Janeiro, 1930, n.o 1, págs. 45-46.

(16). - Saint-Hilaire (Auguste de), Viagem às nascentes do Rio são Francisco e pela Província de Goyaz. São Paulo, 1937. Companhia Editôra Nacional, vol, 2, pág. 67 . 
tras do que na mata de primeira, com insolação de 20 a. $30 \%$ durante o período sêco e apenas duas sinúsias, deixando Jugar à vegetação baixa formada especialmente de gramíneas e ciperáceas. O solo é de terra vermelha, mas pouco humosa e com umidade reduzida, motivo por que, nos meses da estiagem, as árvores perdem as suas fôlhas, ao menos em parte. E' mata sêca que se pode chamar semi-decídua, porque $30 \%$ das árvores perdem as fôlhas, ao passo que na de primeira apenas 3 a $10 \%$.

Aqui já não aparece mais a palmeira guariroba que é uma planta indicadora da mata de primeira classe, mas em geral encontram-se as mesmas árvores que naquela, embora menos desenvolvidas.

Há ainda a mata de terceira classe que é uma espécie de transição para o cerrado. O solo é vermelho, muito arenoso, com pouco humus e guarnecido com vegetação baixa, cipós e hervas. Como essências florestais podem citar-se a paineira (Bombax sp.), aroeira, jacarandá, pau-de-terra, pau santo, pequiá e outros elementos do cerrado (17).

\section{Formações sub-xerófilas}

À vegetação desta categoria pertencem os cerradões. Em regra são constituídos pelas faixas que se estendem entre as matas higrófilas ou se formam na base dos montes. São matas sêcas ou cerrados mais densos. Segundo Waibel (18) o cerradão é o climax do cerrado. As árvores são menos raquíticas que nos cerrados, pois o solo encerra mais umidade, é mais rico, vermelho, humoso, mas muito arenoso; têm 10 a 15 metros de altura e uma densidade que permite apenas uma insolação de 20 a $30 \%$ (19).

Paulo de Souza (20) cita as madeiras seguintes: jacarandá (Machaerium), Cumaru (Dipteryx), Maria-preta (Torrubia), tucaneiro (Vochysia), mangabeira (Hancornia), marmelada (Amajoua), aroerinha (Schinus), angelim (Andira), sapotá (Chrysophyllum), embiruçu (Bombax), resineiro (Protium), paineira (Bombax), pau rôxo (Peltogyne). Waibel menciona ainda as seguintes: pau-terra (Qualea), pau santo (Kielmeyera), pequiá (Caryocar), óleo vermelho (Myroxylon), aroeira (Astronium), sucupira da mata (Bowdichia) e alguns bambus, como sejam: a taboca (Merostachys) e a cam-

(17). - Faissal (Speridiāo), o problema, etc., op. cit., pág. 11.

(18). - Waibel (Leo), op. cit., pág. 543.

(19). - Waibel (Leo), op. cit., pág. 543.

(20). - Souza (Paulo de), op. cit., pág. 45. 
baúva que serve para alimentação de gado e é muitas vêzes cultivado para êste fim. Saint Hilaire (21) encontrou ali também o pau-darco (Tecoma), a claraiba (Cordia), paineira-do-. campo (Pachira marginata) com frutos em julho, mas sem fôlhas, a palmeira macaúba (Acrocomia) e indaiá (Cocos fle-. xuosa) com côcos do tamanho de uma maçã. Falando dos cer-. radões que cobrem os morros revestindo-os com sua bela vegetação compara-os com a mata dizendo que têm pouco vigor e não conseguem dar à paisagem o aspecto severo das regiões. das matas virgens.

\section{Formações xerófilas.}

São características dos lugares excessivamente sêcos, pelo. menos, em grande parte do ano. Os vegetais próprios destas formações são qualificados pela redução do diâmetro das fôlhas, pela perda delas durante o tempo sêco e pelo grande desenvolvimento de órgãos de defesa, como sejam: epiderme pilosa ou vilosa, ou ainda, coberta de cêra. Os troncos defendem-se pela casca grossa sulcada, reforçada de cortiça, e algumas plantas pelas partes subterrânes bastante volumosas, em forma de xilopódios, rizomas, túberas ou bulbos ou então, de raízes longas e profundas (se o terreno o permite). Estes órgãos hipógeos destinam-se ao aprovisionamento com água para o tempo da sêca, porque os dois a quatro meses de chuva durante o ano são por demais escassos para o crescimento dos. vegetais. E' um período de descanso forçado para essas plantas. Graças a êstes órgãos as plantas sobrevivem e resistem. não sòmente aos ardores do sol causticante que dardeja sem. clemência o solo exposto, mas também às queimas que os cam-. pos sofrem anualmente. Desta vida latente os vegetais ressuscitam para uma vida nova logo com as primeiras chuvas ou mesmo algum tempo antes para incontinenti darem flôres e frutos durante os curtos meses de chuva (22).

Fazem parte destas formações o cerrado, o campo sujo e. o campo limpo. São chamadas muitas vêzes simplesmente "campos cerrados".

O cerrado é um campo coberto de árvores distanciadas que não fazem sombra. E' uma formação que se compõe de hervas, sub-arbustos e árvores pequenas retorcidas, parecendo crescerem tímidas e vacilantes, formando no espaço desenhos curio-

(21). - Saint-Hilaire (Auguste de), op. cit., pág. 156.

(22). - Hoehne (F. C.), op. cit., pág. 135; sf. Rawitscher (F. K.), o problema etc., op. cit., pág. 53 . 
sos e extravagantes. O solo exposto sempre ao sol é sêco, pobre, com pouco humus, endurecido, mas poroso, deixando filtrar as águas; é arenoso, de côr vermelha ou cinzenta com tôdas as transições. A crosta superficial do solo é devido às queimas e à ação dos capilares no tempo sêco (23).

Os cerrados cobrem extensão maior que tôdas as categorias de matas decíduas e semi-decíduas reunidas. Uns $75 \%$ do planalto central consistem em cerrados e seus campos inclusos e se estendem até onde os olhos podem alcançar. A composição florística é semelhante em todo Brasil central. Segundo Warming (24) que fêz estudos especializados em Lagoa Santa (Minas), a composição é esta: das 149 famílias botânicas, 120 pertencem à flora florestal, 77 são representadas nos campos e cerrados, 27 são exclusivamente das matas e 2 são restritas aos campos. Dos 753 gêneros por êle encontrados sòmente 82 ocorrem no campo e nos cerrados. A flora da mata é mais rica que a dos campos e cerrados, embora só ocupe áreas pequenas. A mata surge onde há solos férteis, e os campos e cerrados, nos trechos de solos pobres. Segundo êste autor, a flora florestal é mais antiga e mais primitiva que a dos campos cerrados. Poderia dizer-se talvez que a flora campestre é uma flora depauperada e a transformação das matas em campos é antes causada por um processo geológico do que provocada pela interferência humana.

O cerrado é considerado por Warming uma vegetação climax natural, mas Lund e Rawitscher o encaram como climax decaído, tendo sido degradado pelas queimas anuais e pelo pastoreio. Em todo caso, Goiás talvez tenha preservado a sua vegetação original .

Saint Hilaire (25) descreve o planalto goiano como sendo um deserto mais ou menos uniforme, coberto ora de pastagens naturais entremeadas de árvores enfezadas, ora ùnicamente de gramíneas com outras hervas e subarbustos. Achouo muito monótono e por tôda a parte com o mesmo aspecto, especialmente na época da estiagem. Ele escreve:

"Todos os vegetais dessecados pelo ardor do sol tinham um matiz amarelo ou acinzentado que afligia a vista; as flôres tinham desaparecido. Apenas o elegan-

\footnotetext{
(23). - Waibel (Leo), op. cit., págs. 550 e 540 .

(24). - Warming (S.), Ecology of plants. London. Oxford University Press. 1925. (Trad.), cf. idem, Lagoa Santa. Belo Horizonte, 1908, pág. 210; Rawitscher (F. K.), Problema, etc. "Botânica", n.o 4, 1944, págs. 130-135 (25). - Saint Hilaire (Auguste de), op. cit., pág. 20.
} 
te e majestoso buriti que se eleva nas depressões pantanosas, desfazia a ilusão".

Ule (26) que, como outros botânicos antes dêle, estudou bem o cerrado explica que as diferentes espécies se acham de preferência em grupos isolados e menos misturados do que na mata, e que, além das leguminosas e bignoniaceas, predominam sobretudo árvores com fôlhas inteiras e coriáceas. Encontrou as seguintes espécies: Barbatimão (Stryphnodendron obovatum Benth.), Sucupira branca (Pterodon abruptus Benth.), guatambo-do-cerrado (Aspidosperma tomentosum Mart.), copaiba (Copaifera sp.), pimenta do sertão (Xylopia sericea St. Hil.), fôlha santa (Salvertia convallariaeodora St. Hil.), com panículas de quase um metro de comprido; pau-terra (Qualea grandiflora Mart.), murici (Byrsonima sericea DC.). Outras árvores bem distintas são: Pau-paraiba (Simaruba versicolor St. Hil.), coépia (Couepia ovalifolia Benth.), caboatã (Matayba guyanensis Aubl.), pequi (Caryocar brasiliensis Miq.), açoita-cavalo (Luehea paniculata Mart.), estoraque do campo (Styrax floridus Pohl), curriola (Lucuma sp.), ucuuba (Virola sebifera Aubl.), carne-de-vaca (Roupala ovalis Pohl), caxaporra-de-gentio (Terminalia argentea Mart. \& Zucc.), pau santo (Kielmeyera coriacea Mart.) e outras mencionadas por Paulo de Souza (27), como sejam: Peroba-do-campo (Aspidosperma subincanum Mart.), lixeira (Curatella americana L.), faveira (Dimorphandra gardneriana Tul), cagaiteiro (Stenocalyx dysenterica Berg), landim (Calophyllum brasiliense Camb.), jatobá rôxo (Hymenaea sp.), timbó-do-cerrado (Magonia pubes cens St. Hil.), sucupira preta (Bowdichia virgilioides HBK.), baru (Dipteryx alata Schr.), maria-preta (Torrubia tomentosa Casar.), jacaré (Piptadenia gonacantha Mart.), tamboril ou vinhático-do-campo (Enterolobium ellipticum Benth.), pacari (Lafoensia pacari St. Hil.), bacopari (Rheedia sp.), caraiba (Tecoma caraiba Mart.), mutamba (Ghazuma ulmifolia Lam.), etc. Entre as árvores enfezadas há uma que merece ser citada, a que chamam "Árvore-do-papel", porque sua casca perfeitamente branca se compõe de várias camadas separáveis e bastante delgadas que têm a consistência do papel da China. Eleva-se mais ou menos à altura de 5 a 8 pés; seu caule é tortuoso, os galhos que o são igualmente, começam a pequena distância da

(26). - Ule (Ernesto) e Cruls (L.), in Comissão Exploradora do Planalto Central. Relatório apresentado a S. Exa. o Sr. Ministro da Indástria, Viação e Obras Públicas. Rio de Janeiro, 1894, págs. 339-365.

(27). - Souza (Paulo de), op. cit., pág. 46. 
base do tronco; tem uma direção quase vertical e termina por um grande número de galhos curtos e miúdos. E' Tibouchina papyrus (Pohl) Tol., própria só da Serra Dourada já fora do Distrito Federal. Outra árvore bem interessante é sebastiãode-arruda (Physocalymma florida Pohl) com lindas flôres róseas em agôsto com as quais o povo enfeita a igreja e os barracões das quermesses (28).

Dentre a vegetação arbustiva Ule (29) menciona as mimosas (Mimosa digitata Benth.), de que há mais de 50 espécies (incluindo as hervas), os mororós (Bauhinia nitida Benth.) e mais duas dezenas dêstes arbustos chamados também de "Unha-de-vaca" por causa da forma de suas fôlhas; murici (Byrsonima verbascifolia Benth.) sacarolha (Helicteres brevispira St. Hil.), uva-do-campo (Salacia multiflora St. Hil.), quina-do-campo (Strychnos pseudoquina St. Hil.), mangaba (Hancornia speciosa Gomes), a qual fornece borracha de qualidade inferior e dá saborosas frutas; tiborna (Plumeria drastica Mart.) que fornece aos sertanejos um poderoso drástico; galinha-choca (Erythroxylon suberosum St. Hil.), os cajus ou cajueiros-do-campo (Anacardium) de que foram descritas em 1949 três espécies: uma delas com fruto azêdo e as duas outras que St. Hilaire gaba muito devido ao gôsto adocicado e que são muito procurados pela população na época das chuvas quando amadurecem. Uma árvore típica é também a fruta-de-lcho (Solanum lycocarpum St. Hil.) que, como Ule explica é chamada assim por causa dos frutos do tamanho da cabeça dêsse animal. Outra planta característica do cerrado é a canela-de-ema (Vellosia) de que Pohl (30) descreve cinco espécies. E' arborescente bifurcando-se várias vêzes e cujos ramos revestidos de escama terminam por uma bela flor protegida por um penacho de fôlhas lineares agitadas pelo vento mais leve. Algumas vêzes - diz Saint Hilaire - ocupa espaços consideráveis, outras vêzes, algumas árvores raquíticas erguem-se aqui e acolá no meio desta singular monocotiledônea.

Poderia citar-se muitas outras espécies, entre árvores e arbustos, mas elas só têm interêsse puramente científico e, por isso as omitiremos.

(28). - Saint Hilaire (Auguste de), op. cit., págs. 38, 63, 100, 205. Cf. Flora Brasiliensis, de Martius 14(3), pág. 256.

(29). - Cruls (L.), op. cit., págs. 237-238.

(30). - Pohl, in Saint Hilaire, Flora Brasiliae Meridionalis 1829. 3, pág. 123. Cf. Pohl (Johannes Emmanuel), Plantarum Brasiliae Icones et Descriptiones. Vindobonae, 1827 , vols. 1 e 2. 
Entre as hervas que só na época das chuvas atraem a atenção, Ule encontrou entre a vegetação do cerrado muitas leguminosas, polygalaceas, euphorbiáceas e, naturalmente, muitas gramíneas e cyperaceas. Pohl e Saint Hilaire na sua "Flora", descrevem inúmeras hervas do cerrado que crescem também nos campos limpos.

No meio do cerrado, alternando com trechos de matas ciliares, capões e a vegetação típica arborescente das formações xerófilas, encontram-se, às vêzes, campos de capim rasteiro. $\mathrm{Na}$ época da estiagem, graças à exposição permanente dos raios solares e dos ventos dominantes, especialmente as gramíneas e cyperaceas, ficam encrustadas de sílica como meio de defesa contra o ambiente adverso (31). Esses campos parecem-se com um deserto se não fôsse o gado pastando, no tempo das chuvas, pois, êsses campos são aproveitados para a criação do gado (32) .

As gramíneas são, segundo Paulo de Souza (33) as seguintes: Capim-de-raiz (Bouteloua americana (L.) Scribn.), C. amargoso (Trichachne insularis (L.) Nees), C. pé-de-galinha (Eleusine indica Gaertn.), C. rabo-de-raposa (Andropogon bicornis L.), C. papuan (Paspalum conjugatum Berg), C. jaraguá (Hyparrhenia rufa (Nees), Stapf), C. gordura (Melinis minutiflora Beauv.), C. barba-de-bode (Aristida pallens Cav.), etc.

A presença, todavia, desta última gramínea nos campos acusa, segundo Loefgren (34), o esgotamento superficial da terra; resiste às queimadas e é um índice da passagem do homem pela região onde cresce. E A. de Saint Hilaire (35) afirma que também o capim gordura é de origem antropocórea, pois, se prende à passagem de antigas lavouras nessa região.

Aliás, os campos limpos são bastante raros, pois, predominam os campos sujos, como chamam aquêles que são entremeados de arbustos e palmeiras, como seja a palmeira anã (Attalea exigua Dr.), de um a dois metros de altura que sobrepuja as soqueiras de gramíneas, e outras moitas de arbustos surgem no meio da vegetação rasteira, geralmente sôbre montículos de cupim. Dawson, botânico da "Machris Brazilian Expedition", vê nos campos sujos uma deterioração do cerrado

\footnotetext{
(31). - Hoehne (F. C.), op. cit., pág. 134.

(32). - Rodrigues Ferreira (Manuel), op. cit., pág. 145.

(35). - Souza (Paulo de), op. cit., pág. 45.

(54). - Loefgren (Alberto), Contribuição para a flora paulista: Regiáo campestre, in "Boletim da Comissão Geográfica e Geológica de São Paulo". 1890, n.o 5, pág. 28.

(35). - Saint Hilaire (Auguste de), op. cit., págs. 66, 177, 178.
} 
devida ao fogo, de maneira que o cerrado não seria uma vegetação-climax, pois há nítida gradação de uma fácies à outra. Na opinião dêle o cerrado transformar-se-ia em mata de segunda classe, caso o fogo não estorvasse a vegetação (36).

Do cerrado distingue-se a caatinga, com a qual se assemelha esta formação pela presença de uma vegetação agressiva de espinheiros, cactáceas e bromeliáceas terrestres. No cerrado todavia encontram-se algumas espécies de Dyckia, Aechmea, Pitcairnea, mas não o caroá e macambira, tão características da caatinga. A "Machris Brazilian Expedition" todavia encontrou também cactáceas constituindo formações semelhantes às da caatinga em rochas areníticas que afloram no meio da vegetação do cerrado. Colheu duas espécies de $\mathrm{Ce}$ phalocereus entre bromeliaceas e samambaias, como sejam: Anemia, Polypodium, Pteris, etc. (samambaias) e Bromelia, Dyckia, etc. (Bromeliaceas) (37).

\section{Brasília.}

Ao norte de Brasília elevam-se os desfiladeiros da Serita dos Pireneus ( 1370 metros $\mathrm{s} / \mathrm{m}$ ), que se prolongam atravessando o Distrito Federal até a cidade de Formosa, formando quase sempre chapadões de 1.000 a 1.200 metros de altitude. Dêstes desfiladeiros faz parte a Chapada da Contagem, sobranceira a Brasília, com 1.100 a 1.280 metros. A oeste da nova Capital, perto de Brasilândia, encontra-se a Chapada do Rodeador, com 1.320 metros de altitude. A Chapada da Contagem divide-se em direção do leste em duas cadeias, a saber, o Planalto de Larga, por onde passa a estrada Brasília-Planaltina-Formosa, e os Planaltos de Retiro e São Gonçalo. Ao sul de Brasília surgem os Planaltos de Riacho Fundo e Papudo, todos êles com 1.200 metros de altitude mais ou menos.

Brasília fica numa chapada compreendida entre os Rios Torto e Gama, com mais ou menos 1.000 metros de altitude. A rodovia São Paulo-Brasília passa pelo Planalto de Taguatinga, de 1.200 metros, de onde se enxerga de longe a nova Capital, e a rodovia Brasília-Belo Horizonte que tem direção NS, desce de um planalto da mesma altitude.

Os planaltos ou chapadas são limitadas pelos vales por onde correm inúmeros córregos, ribeirões, riachos e rios, com sua

(36). - The Machris Brazilian Expedition, op. cit., n.o 2, pág. 11; n.o $17 ;$ n.o 35. (37). - The Machris Brazilian Expedition, op. cit., n. 0 . 
vegetação própria, quase sempre de matas. Os Rios Torto e Gama, entre os quais se localiza Brasília, formando lagos artificiais, desaguam no Rio Paranoá que, por sua vez, se lança no Rio São Bartolomeu e corre para o sul, como afluente do Paranaíba e, depois, do Paraná (38).

A vegetação de Brasília é de cerrado com essas árvores raquíticas, como já foram descritas, e que ainda agora circundam o terreno não edificado. As curiosas Vellosia ou Canela-de-ema encostam-se até nos muros dos edifícios, como que protestando contra a invasão do homem no sacrário da natureza de Deus.

$\mathrm{Na}$ chapada de Brasília, bem como nas outras, predominam, segundo Ule, árvores e arbustos sociais, tais como o paude-tucano (Vochysia pruinosa Pohl.), marmelada-de-campo (Plenckia populnea Reiss.), muitas espécies congêneres da mandioca (Manihot), descritas por Pohl, leiteiro (Euphorbia sarcodes Reiss.), jacatirão (Miconia sp.), leguminosas, como pelego-de-velha (Calliandra macrocephala Benth.), Mimosa setosissima Taub. e Cassia sp., a ucuuba (Virola sebifera Aubl.), jatobá (Hymenaea sp.), murici (Byrsonima sp.), candeia (Lychnophora ericoides Mart., Piptocarpha rotundifolia Bak., e Vanillosmopsis Pohlii Bak.), pau-paraíba (Simaruba versicolor St. Hil.), pitanga miúda (Aulomyrcia rubella Berg), fruto de cotia (Esenbeckia pumila Pohl), bola-de-neve (Guettarda viburnoides Cham.), caroba (Jacaranda simicifolia Schum.), etc.

Segundo Glaziou (39), muitos vegetais das chapadas assemelham-se à flora alpestre do Itatiaia e da Serra dos Órgãos, contando entre êles na chapada de Brasília o pinheiro bravo (Podocarpus Lamberti $\mathrm{Kl}$.), muitas Melastomatáceas dos gêneros Lavoisiera, Microlicia, Tibouchina, Siphanthera, etc., e Ericáceas dos gêneros Gaultheria, Gaylussacia, Leucothoe, etc.

A macega alta, às vêzes, densa e agressiva que surge entre os arbustos e árvores dificulta o trânsito pelo campo, porque fica dura na época da sêca. Compõe-se de gramíneas dos gêneros Panicum, Paspalum, Andropogon, etc. e, entre elas outras hervas graminóides, como seja Xyris graminosa Pohl. de um metro de altura, com uma espécie de bolota na extremidade, e também o belíssimo Paepalanthus speciosus Kcke, com sua graciosa umbela de flôres brancas pequeninas, também de altura avantajada; a perpétua-do-mato (Gomphrena phylla Pohl e Telanthera ramosissima Moq.), etc.

\footnotetext{
(38). - VIde Mapa do Nôvo Distrito Federal. Rio de Janeiro, 1958. Eáitado pelo Instituto Brasileiro de Geografia e Estatística.

(39). - Glaziou (A.), in Cruls (L.), op. cit., 1947, pág. 9.
} 
Essa macega é belíssima no tempo das chuvas, quando tôdas as hervas estão em flor, e bafejadas pelo vento estão em ondulações permanentes como mar tranqüilo, embalsamando o ar com suas exalações de oxigênio e óleos voláteis (40).

Esta vestimenta da terra protege o solo contra o vento, mas onde falta, como nas partes edificadas ou revolvidas pelos bindozers para a construção de estradas, o vento carrega as partículas terrosas e levanta nuvens de pó que não só incomoda, mas tira a vista e penetra nos edifícios. Por isso, a terra não pode ficar sem cobertura: as margens das estradas devem ser ajardinadas, primeiramente com gramíneas e, depois, com arbustos, e tôda a área construída e por construir deve ser defendida contra os ventos por árvores formando anteparos contra a erosão eólica.

D. BENTO JOSE' PICKEL O.S.B. (41)

Ex-biologista do Serviço Florestal do Estado de São Paulo.

*

\section{BIBLIOGRAFIA CONSULTADA.}

Aubreville (A.). - Les forêts du Brésil, in "Bois et forêts des tropiques". Paris, 1958. N.o 60 .

Campos (Gonzaga de). - Mapa florestal do Brasil. Rio de Janeiro, 1910 .

Correa de Melo (Beatriz Célia). - Mapa climático do sudeste do Planalto Central, in "Boletim Geográfico", 1952. N.o 109.

Couto de Magalhães (General). - Viagem ao Araguaia. São Paulo, 1939 (Brasiliana 28).

Cruls (L.). - Relatório da Comissão Exploradora do Planalto Central do Brasil: Notícia botânica pelo Dr. E. Ule. Rio de Janeiro, 1894, pp. 339-365.

Idem. - Relatório da Comissão Exploradora do Planalto Central do Brasil. São Paulo, 1946 (Brasiliana 258).

Faissal (Speridião) . - O Matogrosso de Goiás, in "Boletim Geográfico, 1949. N.o 79 .

(40). - "A Gazeta". São Paulo, 21 de abril de 1960.

(41). - D. Bento José Pickel O.S.B., do Mosteiro de São Bento desta Capital, nasceu em Markelsheim (Alemanha) aos 28 de julho de 1890, velo para o Brasil em 14 de novembro de 1908 e em 17 de fevereiro naturalizou-se cidadão brasileiro. Biologista, botânico, cientista, depois de ocupar cargos os mais expressivos no campo de sua especialidade, aposentou-se, em 1961, como Diretor do Museu Florestal "Octávio Vechi", do Serviço Florestal do Estado de São Paulo. Esse nosso colaborador faleceu nesta Capital aos 4 de abril de 1963 e a Revista de História, como colaboração para a publicação de suas obras, resolveu estampar, como sua derradeira homenagem, êste artigo do grande interêsse para a caracterização da nova Capital Federal (Nota đa Ređação). 
Idem. - A região de Uruana, in "Boletim Geográfico", 1949. ․ 79. Idem. - Vegetação e solos no sudeste do Planalto Central. Rio de Janeiro, 1953. Edição do Instituto Brasileiro de Geografia e Estatística.

Idem. - o problema do desenvolvimento agrícola do sudeste do Planalto Central do Brasil, in "Revista Brasileira de Geografia", 1957, 19 (1).

A Gazeta. São Paulo, 1960. Edição de 21 de abril e seguintes.

Hcehne (F. C.). - A flora do Brasil, in "Recenseamento do Brasil" 1922, vol. 1 .

Kruse (Hermann). - Goyaz, das wahre Herz Brasiliens. São Paulo, 1936.

Loefgren (A.). - Contribuição para a flora paulista: Região eampestre, in "Boletim da Comissão Geográfica e Geológica de São Paulc". N.० 5, 1890.

Macedo Soares Guimarães (Fábio). - Relêvo do Brasil, in "Boletim Geográfico", 1943. 1 (4).

Idem. - o Planalto Central e o problema da mudança da Capital do Brasil, in "Revista Brasileira de Geografia", 1949. 11 (4).

Pohl (Johannes Emmanuel). - Plantarum Brasiliae icones et descriptiones. Vindobonae, 1827. 2 tomos.

Rawitscher (F. K.). - Problemas de fitoecologia, in "Boletim da Faculdade de Filosofia, Ciências e Letras n. ${ }^{\circ} \mathrm{s} 27$ e 41,1942 e 1944 .

Rodrigues Ferreira (Manuel). - Nos serțóes do lendário Rio das Mortes. São Paulo, 1946. Editôra do Brasil S. A.

Saint Hilaire (Augusto de). - Viagem às nascentes do Rio São Francisco e pela Província de Goiás. São Paulo, 1937 (Brasikiana 78).

Smith (Herbert) . - A região dos campos no Brasil. 1885.

Souza (Paulo de). - Apontamentos sôbre a flora de Goiás, in "Revista Florestal", Rio de Janeiro, 1930. 2 (1).

The Machris Brazilian Expedition, in "Contrib. in Science". Los Argeles County Museum, 1957-1960. N. ${ }^{\circ}$ 1-35.

Waibel (Leo). - Vegetation and land use in the Planalto Central do Brasil, in "Geog. Review"; New York, 1948. Outubro.

Warming (E.). - Ecology of plants. London. Oxford University Press. 1925.

Mapa do Nôvo Distrito Federal. Organização do Escritório de Representação do Govêrno de Goiás no Rio de Janeiro, 1958. Edição do Instituto Brasileiro de Geografia e Estatística. 


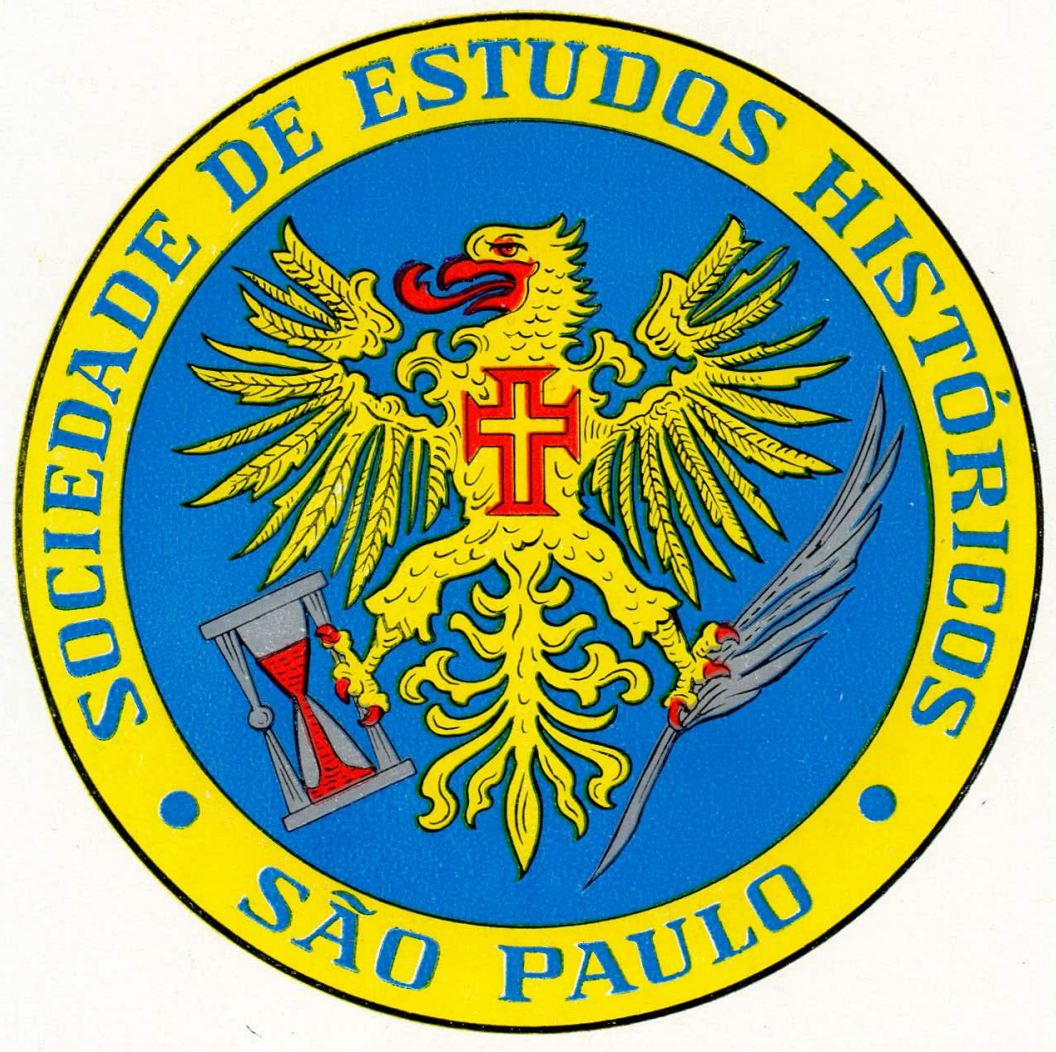

